\title{
PRODUKTIVITAS PEKERJA DALAM PEKERJAAN PLESTERAN DINDING BATA DENGAN METODE CREW BALANCE CHART
}

\author{
Indra Pratama Suharto ${ }^{1}$ dan Hendrik Sulistio ${ }^{2}$ \\ ${ }^{1}$ Program Studi Sarjana Teknik Sipil, Universitas Tarumanagara, Jl. Letjen S. Parman No.1 Jakarta \\ indra.325150151@stu.untar.ac.id \\ ${ }^{2}$ Program Studi Sarjana Teknik Sipil, Universitas Tarumanagara, Jl. Letjen S. Parman No.1 Jakarta \\ hendriks@ft.untar.ac.id
}

\begin{abstract}
The productivity of workers is one of the parameters for the success of a project. With the crew balance chart method, every worker's activity in the field will be displayed, and the results of the observations will be optimized. Observations were made on brick wall plastering in Cempaka Baru residential construction project, which consisted of 2 work groups. The results volume of plastering done by the 1st group, the productivity on the first day was $1.195 \mathrm{~m}^{2} /$ hour, and the second day was $3.987 \mathrm{~m}^{2} /$ hour, where if the worker was in ideal conditions the volume that could be produced was $1.647 \mathrm{~m}^{2} /$ hour on the first day and $6.869 \mathrm{~m}^{2} /$ hour on day 2. Whereas in the second group the productivity on the first day was $0.451 \mathrm{~m}^{2} /$ hour, and on the second day it was $1.812 \mathrm{~m}^{2} / \mathrm{hour}$, where if the worker was in ideal conditions the volume that could be produced was $0.643 \mathrm{~m}^{2} /$ hour on the first day and $2.489 \mathrm{~m}^{2} /$ hour on the second day. The low productivity of workers caused the contractor to suffer a loss of Rp. 339,782.00 on wall plastering work were observed.
\end{abstract}

Keywords: productivity; brick wall plastering; crew balance chart

\begin{abstract}
ABSTRAK
Produktivitas pekerja pada proyek konstruksi merupakan salah satu parameter keberhasilan suatu proyek. Dengan metode crew balance chart akan ditampilkan setiap kegiatan pekerja yang dilapangan, dan dari hasil pengamatan tersebut akan dilakukan optimasi, untuk meningkatkan produktivitas pekerja. Pengamatan dilakukan pada pekerjaan plesteran dinding bata pada proyek pembangunan rumah tinggal Cempaka Baru, yang terdiri dari 2 group kerja. Dari hasil volume plesteran yang dikerjakan group ke-1, produktivitas dihari pertama sebesar 1,195 $\mathrm{m}^{2} / \mathrm{jam}$, dan dihari ke-2 sebesar 3,987 $\mathrm{m}^{2} / \mathrm{jam}$ yang dimana bila pekerja dalam kondisi ideal, volume yang dapat dihasilkan sebesar 1,647 $\mathrm{m}^{2} / \mathrm{jam}$ dihari pertama dan $6,869 \mathrm{~m}^{2} / \mathrm{jam}$ dihari ke-2. Sedangkan pada group ke-2 produktivitas dihari pertama sebesar $0,451 \mathrm{~m}^{2} / \mathrm{jam}$, dan dihari $\mathrm{ke}-2$ sebesar $1,812 \mathrm{~m}^{2} / \mathrm{jam}$, yang dimana bila pekerja dalam kondisi ideal volume yang dapat dihasilkan sebesar 0,643 $\mathrm{m}^{2} / \mathrm{jam}$ dihari pertama dan $2,489 \mathrm{~m}^{2} / \mathrm{jam}$ dihari ke-2. Rendahnya produktivitas yang dihasilkan pekerja mengakibatkan kontraktor mengalami kerugian sebesar Rp. 339.782,00 pada pekerjaan plesteran dinding yang diamati.
\end{abstract}

Kata kunci: produktivitas; plesteran dinding bata; crew balance chart

\section{PENDAHULUAN}

Seiring dengan berjalannya waktu proyek konstruksi seperti tidak ada habisnya dari waktu ke waktu. Permintaan akan pekerjaan konstruksi akan selalu ada selama manusia masih menjalankan aktivitasnya sehari-hari. Menurut (Purnomo, Pengantar Manajemen Proyek, 1999), proyek merupakan suatu rangkaian kegiatan yang harus diselesesaikan sesuai perjanjian awal dan memenuhi persyaratan mutu, waktu, dan biaya yang telah disepakati. Disisi lain dengan banyaknya proyek konstruksi yang sedang berjalan, kontraktor dituntut agar dapat menyelesaikan pekerjaannya tepat waktu dengan hasil yang optimal.

Selama ini keterlambatan pada proyek konstruksi merupakan hal yang sering sekali dijumpai. Salah satu penyebab keterlambatan pada proyek konstruksi itu sendiri ialah produktifitas yang dihasilkan oleh pekerja rendah (W. I. Ervianto). Faktor tenaga kerja merupakan salah satu faktor dominan yang mempengaruhi dalam menentukan progres pekerjaan. Rendahnya kesadaran pekerja akan pentingnya produktivitas mengakibatkan rendahnya hasil pekerjaan yang diperoleh (Muchdarsyah, 1992). Rendahnya produktivitas yang dimiliki oleh tenaga kerja, 
kontraktor dituntut untuk melakukan peningkatan produktivitas. Akan tetapi, banyaknya faktor-faktor yang mempengaruhi produktivitas menyebabkan usaha peningkatan produktivitas menjadi tidak mudah. Keadaan seperti ini sering kali terjadi yang disebabkan oleh banyaknya idle time yang dilakukan para pekerja, sehingga progres pekerjaan dari suatu proyek menjadi terhambat dan dapat mengakibatkan keterlambatan. Produktifitas pekerja pada proyek konstruksi sulit untuk kita paksakan agar pekerja dapat memaksimalkan waktu kerjanya, idle time pada pekerjaan proyek konstruksi pasti selalu terjadi.

Rendahnya produktivitas yang dihasilkan oleh pekerja membuat progress suatu pekerjaan menjadi terlambat. Dengan adanya fenomena tersebut produktifitas pekerja perlu dianalisis lebih lanjut, guna untuk mendapatkan hasil yang diharapkan sesuai durasi yang telah ditentukan. Durasi merupakan salah satu parameter yang dapat dijadikan suatu patokan keberhasilan proyek. Oleh sebab itu dalam sebuah proyek dibutuhkan pengendalian waktu yang optimal agar proyek dapat selesai tepat pada waktunya.

Pendataan hasil pekerjaan dilapangan dapat digunakan untuk menganalisis seberapa besar volume yang didapat dan seberapa besar idle time yang terjadi. Hasil analisis tersebut dapat disajikan dalam bentuk diagram Crew Balance Chart. Hasil dari analisis tersebut dapat digunakan untuk menentukan waktu durasi efektif yang dilakukan pekerja dan dapat memperhitungkan kerugian yang ditimbulkan akibat kurang produktifnya pekerja (Caroline).

Ketidaksesuaian produktivitas yang diharapkan dengan hasil yang didapatkan mengakibatkan rendahnya hasil pekerjaan yang diperoleh (Muchdarsyah, 1992). Keadaan seperti ini sering kali terjadi yang disebabkan oleh banyaknya idle time yang dilakukan para pekerja, sehingga progres pekerjaan dari suatu proyek menjadi terhambat dan dapat mengakibatkan keterlambatan.

Dengan adanya idle time yang dilakukan oleh para pekerja tidak hanya berdampak pada keterlambatan progres pekerjaan, namun juga dapat mengakibatkan penambahan upah pekerja yang dikarenakan tidak sesuai dengan upah yang dikeluarkan dengan hasil yang diharapkan.

Dari identifikasi masalah yang ada, terdapat rumusan masalah yang akan dibahas, antara lain:

1. Bagaimana cara menentukan koefisien pekerja yang ideal terutama pada pekerjaan plesteran pada dinding bata ringan dengan menggunakan metode Crew Balance Chart?

2. Bagaimana produktivitas yang dihasilkan pekerja terhadap waktu ideal yang dapat dikerjakan?

3. Berapa kerugian yang ditimbulkan dengan adanya idle time yang dilakukan pekerja?

Tujuan dari penulisan ini melakukan optimasi produktivitas pekerja pada pekerjaan plesteran dinding bata dengan diagram crew balance chart sehingga dapat ditentukan:

1. Menghitung waktu kerja tidak produktif dan menentukan koefisien pekerja yang ideal berdasarkan pengamatan dilapangan.

2. Menampilkan produktivitas yang dihasilkan pekerja terhadap waktu ideal yang dapat digunakan.

3. Menghitung kerugian yang terjadi akibat adanya idle time yang dilakukan pekerja berdasarkan pengamatan dilapangan.

Penulisan ini mencakup dan dibatasi oleh:

1. Optimasi waktu dari hasil pengamatan dilapangan pada pekerjaan plesteran dengan pemodelan diagram Crew Balance Chart.

2. Pengamatan yang ditinjau hanya pada pekerjaan plesteran pada dinding bata ringan.

3. Data yang diolah sesuai dengan hasil pengamatan dilapangan yang didapat pada proyek pembangunan rumah Tinggal Cempaka Baru.

\section{METODE PENELITIAN}

\section{Populasi dan sampel}

Dalam penelitian ini, populasi yang digunakan ialah proyek konstruksi di Jakarta, dan untuk sampel yang digunakan dalam pengambilan data untuk penelitian ini adalah pekerjaan plesteran dinding bata pada proyek pembangunan Rumah Tinggal Cempaka Baru.

\section{Metode pengumpulan data}

Pada penelitian ini, data yang didapat pada pekerjaan plesteran dinding bata ringan merupakan data kuantitatif, data tersebut berupa hasil pengamatan langsung dilapangan dalam bentuk jumlah pekerja yang mengerjakan plesteran pada bagian dinding tertentu, dan durasi yang dibutuhkan untuk menghasilkan volume tertentu. Durasi yang ditinjau tidak hanya sebatas berapa lama waktu yang dibutuhkan pekerja menghasilkan volume tertentu, 
melainkan durasi yang diamati terpisah menjadi waktu produktif pekerja mengerjakan pekerjaan tersebut, dengan waktu tidak produktif pekerja.

Pengamatan juga dibantu dengan menggunakan alat bantu video camera dan stopwatch selama pengamatan pada pekerjaan plesteran dinding berlangsung. Hasil dari pengamatan tersebut akan ditampilkan dalam bentuk diagram crew balance chart sesuai kegiatan yang dilakukan setiap pekerja yang diamati. Untuk melengkapi data yang dibutuhkan saat mengolah data, maka wawancara dilakukan kepada pekerja dilapangan dan pihak yang terkait, guna untuk melengkapi hasil dari penelitian ini.

\section{Metode analisis data}

Dalam menganalisis dari data hasil pengamatan pada pekerjaan plesteran dinding bata yang telah didapat, data tersebut akan diolah melewati 2 tahap yakni dengan menggunakan diagram crew balance chart kemudian dilanjut dengan menganalisis optimasi yang dapat diterapkan pada pekerjaan tersebut.

\section{Crew balance chart method}

Pada diagram crew balance chart akan ditampilkan hasil data pengamatan dilapangan dari setiap subkegiatan pada pekerjaan plesteran dinding. Dari data tersebut akan diolah untuk mendapatkan persentase waktu produktivitas pekerja dan persentase idle time yang terjadi. Hasil persentase tersebut akan ditampilkan dalam tabel rekapitulasi yang akan menampilkan persentase waktu produktif dan persentase waktu tidak produktif per satuan waktu, yang nantinya akan digunakan untuk menentukan nilai koefisien dari masing - masing pekerja, berikut contoh tabel rekapitulasi yang akan digunakan dapat dilihat pada tabel 1 .

Tabel 1. Rekapitulasi waktu

\begin{tabular}{|c|c|c|c|c|c|c|c|}
\hline Tenaga & Kegiatan & \multicolumn{2}{|c|}{ Waktu Produktif } & & \multicolumn{3}{|c|}{ Waktu tidak produktif } \\
\hline & & Observasi & \multirow{2}{*}{$\begin{array}{c}\text { Rata - rata } \\
X_{A 1}+X_{B 1}\end{array}$} & $\%$ & Observasi & Rata - rata & \multirow{2}{*}{$Z^{\prime} 1$} \\
\hline & & XA1 & & $\mathrm{Z}_{1}$ & YA1 & $Y_{A 1}+Y_{B 1}$ & \\
\hline & & Хв1 & $n$ & & YB1 & \multirow{2}{*}{$\begin{array}{c}n \\
Y_{A 2}+Y_{B 2}\end{array}$} & \multirow[b]{2}{*}{$Z^{\prime} 2$} \\
\hline \multirow[t]{4}{*}{$\mathrm{C}$} & Tukang & $\mathrm{XA2}$ & $X_{A 2}+X_{B 2}$ & $\mathrm{Z}_{2}$ & YA2 & & \\
\hline & & Хв2 & \multirow{2}{*}{$\begin{array}{c}n \\
X_{A m}+X_{B m}\end{array}$} & & YB2 & \multirow{2}{*}{$\begin{array}{c}n \\
Y_{A m}+Y_{B m}\end{array}$} & \multirow[b]{2}{*}{$Z^{\prime} m$} \\
\hline & & XAm & & $\mathrm{Zm}$ & YAm & & \\
\hline & & $\mathrm{XBm}$ & $n$ & & YBm & $n$ & \\
\hline \multicolumn{3}{|c|}{ Rekapitulasi waktu total } & $\Sigma\left(\frac{X_{A}+X_{B}}{n}\right)$ & $\Sigma \mathrm{Z}$ & & $\Sigma\left(\frac{Y_{A}+Y_{B}}{n}\right)$ & $\Sigma Z^{\prime}$ \\
\hline
\end{tabular}

Keterangan:

$\mathrm{X}_{\mathrm{Am}}=$ waktu dasar pekerja $\mathrm{C}$ saat jam $\mathrm{A}$ pada sub kegiatan $\mathrm{m}$ saat observasi

$\mathrm{X}_{\mathrm{Bm}}=$ waktu dasar pekerja $\mathrm{C}$ saat jam $\mathrm{B}$ pada sub kegiatan $\mathrm{m}$ saat observasi

$\mathrm{Y}_{\mathrm{Am}}=$ waktu tidak produktif pekerja $\mathrm{C}$ saat jam $\mathrm{A}$ pada sub kegiatan $\mathrm{m}$ saat observasi

$\mathrm{Y}_{\mathrm{Bm}} \quad=$ waktu tidak produktif pekerja $\mathrm{C}$ saat jam $\mathrm{B}$ pada sub kegiatan $\mathrm{m}$ saat observasi

$\mathrm{n} \quad=$ rata - rata waktu jam $\mathrm{A}$ dan jam $\mathrm{B}$

$\mathrm{Z}_{\mathrm{m}}=$ persentase waktu produktif

$\mathrm{Z}_{\mathrm{m}}=$ persentase waktu tidak produktif

$Z m=\frac{\text { waktu produktif rata-rata sub kegiatan } m}{\text { waktu dasar rata-rata sub kegiatan } m} \times 100 \%$

$Z^{\prime} m=\frac{\text { waktu tidak produktif rata-rata sub kegiatan } m}{\text { waktu dasar rata-rata sub kegiatan } m} \times 100 \%$

\section{Optimasi produktivitas pekerja dengan diagram crew balance chart}

Dari data yang telah didapat akan diolah untuk menentukan waktu ideal dari pekerjaan plesteran dinding. Optimasi produktivitas akan dianalisis guna untuk mendapatkan kondisi dimana waktu jam kerja dapat digunakan 
semaksimal mungkin. Perhitungan produktivitas pekerja terdiri dari 2 cara, yakni perhitungan produktivitas dengan cara melihat hasil kerja dilapangan, dan perhitungan produktivitas tanpa idle, atau disebut kondisi ideal.

Produktivitas kondisi lapangan=

$$
\text { Produktivitas }=\frac{\text { total luasan plesteran dinding yang dikerjakan }}{\text { total durasi pekerjaan }}
$$

Produktivitas kondisi ideal $=$

$$
\frac{\% \text { waktu produktif max }}{\text { rata }- \text { rata } \% \text { waktu produktif pekerja }} \times \text { produktivitas pekerja }
$$

\section{Analisis peningkatan produktivitas terhadap durasi kerja}

Analisis peningkatan produktivitas merupakan suatu analisis yang dapat mengetahui durasi ideal yang seharusnya dikerjakan untuk menghasilkan suatu pekerjaan sesuai dengan progres yang telah direncanakan. Durasi kerja ideal itu dapat dihitung dengan menggunakan rumus sebagai berikut:

$$
\frac{\text { produktivitas dilapangan }}{\text { produktivitas tanpa idle }} x \text { total waktu kerja }
$$

\section{Analisis upah kerja}

Perhitungan analisis pembayaran upah pekerja didapat dari koefisien pekerja, yang dimana koefisien tersebut didapat dari waktu produktif pekerja selama pengerjaan plesetran dinding bata berlangsung. Analisis upah pekerja dapat dihitung dengan rumus:

$$
\text { Upah pekerja }=\text { koefisien } \mathrm{x} \text { harga upah harian pekerja }
$$

\section{HASIL DAN PEMBAHASAN}

\section{Hasil pengumpulan data penelitian}

Pada penelitian ini objek pengamatan dilakukan pada dua tempat pengerjaan yang berbeda, dengan setiap tempat pengerjaan dikerjakan oleh pekerja yang berbeda. Waktu dari setiap tempat yang diamati juga memiliki durasi yang berbeda-beda, karena adanya perbedaan volume yang dikerjakan. Pengamatan dilakukan selama 4 hari, yang terdiri dari 2 hari pertama dilakukan pengamatan pada pekerjaan plesteran bagian belakang rumah, dan 2 hari berikutnya dilakukan pengamatan pada pekerjaan plesteran bagian depan rumah. Pada pekerjaan plesteran dinding bata ini dilakukan oleh 2 orang pekerja disetiap tempat yang diamati, yang terdiri dari tukang dan kenek (pembantu tukang). Hasil dari pekerjaan plesteran dinding yang dimati dapat dilihat pada gambar 1.

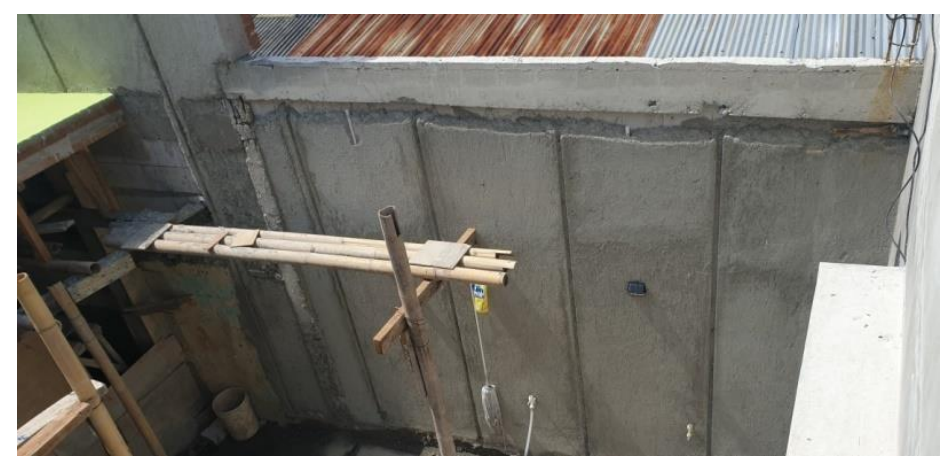

Gambar 1. Hasil pekerjaan plesteran

\section{Data hasil pengamatan lapangan}

Hasil pengamatan pada pekerjaan plesteran ini dimulai dari persiapan bidang yang ingin diplester, lalu dilanjut dengan membuat kepalaan terlebih dahulu sebelum pekerjaan plesteran, membuat adukan, sampai pengerjaan plesteran dinding itu sendiri. Item pekerjaan tersebut dikerjakan sesuai urutannya dan dari setiap item pekerjaan tersebut dicatat waktu durasinya seperti pada tabel 2. 
Tabel 2. Contoh hasil pengamatan lapangan pada pekerjaan plesteran dinding bata

\begin{tabular}{ccccc}
\hline \multicolumn{2}{c}{ Waktu } & Pekerja A & Pekerja B \\
\hline 0 & - & 513 & Persiapan & Persiapan \\
\hline 513 & - & 668 & Persiapan & Menunggu \\
\hline 668 & - & 880 & Persiapan & Persiapan \\
\hline 880 & - & 894 & Persiapan & Menunggu \\
\hline 894 & - & 1150 & Persiapan & Bantu Tukang \\
\hline 1150 & - & 1276 & Persiapan & Menunggu \\
\hline 1276 & - & 1442 & Persiapan & Menunggu \\
\hline 1442 & - & 1532 & Persiapan & Membuat / Ambil Adukan \\
\hline 1532 & - & 1542 & Persiapan & Membuat / Ambil Adukan \\
\hline 1542 & - & 1573 & Idle & \\
\hline
\end{tabular}

\section{Perhitungan dan rekapitulasi}

Dari data yang diperoleh akan dibagi antara waktu produktif dan waktu tidak produktif. Dari masing - masing bagian tersebut akan dihitung persentasenya untuk mengetahui koefisien masing - masing pekerja disetiap harinya. Pencatatan waktu produktif dimulai pada saat pekerja sedang melakukan serangkaian dari kegiatan pekerjaan plesteran itu sendiri, yang dimulai dari persiapan, membuat adukan, membuat kepalaan, dan pekerjaan plesteran dinding itu sendiri. Diluar pekerjaan tersebut akan dimasukan kedalam pencatatan waktu tidak produktif pekerja. Pada tabel 3 dapat dilihat rekapitulasi waktu tenaga kerja, yang dimana hasil tersebut akan dijadikan acuan untuk menentukan koefisien pekerja.

Tabel 3. Rekapitulasi waktu kegiatan plester dinding bata hari ke- 1

\begin{tabular}{|c|c|c|c|c|c|c|}
\hline \multirow[b]{2}{*}{ Nama } & \multirow[b]{2}{*}{ Kegiatan } & \multicolumn{2}{|c|}{ Waktu produktif } & \multicolumn{2}{|c|}{ Waktu tidak produktif } & \multirow{2}{*}{$\begin{array}{c}\text { Koefisien } \\
\%\end{array}$} \\
\hline & & Waktu (detik) & $\begin{array}{c}\text { Observasi } \\
\text { (detik) }\end{array}$ & $\begin{array}{l}\text { Observasi } \\
\text { (detik) }\end{array}$ & $\%$ & \\
\hline \multirow{11}{*}{$\mathbf{A}$} & \multirow{11}{*}{ Tukang } & $0-1800$ & 1757 & 43 & 0,221684 & \multirow{12}{*}{88,25592} \\
\hline & & $1800-3600$ & 1763 & 37 & 0,190751 & \\
\hline & & $3600-5400$ & 1654 & 146 & 0,752694 & \\
\hline & & $5400-7200$ & 1784 & 16 & 0,082487 & \\
\hline & & $7200-8597$ & 1397 & 0 & 0 & \\
\hline & & $12197-13997$ & 1724 & 76 & 0,391813 & \\
\hline & & $13997-15797$ & 1557 & 243 & 1,252771 & \\
\hline & & $15797-17597$ & 1593 & 207 & 1,067175 & \\
\hline & & $17597-19397$ & 1326 & 474 & 2,443677 & \\
\hline & & $19397-21197$ & 1462 & 338 & 1,742538 & \\
\hline & & $21197-22997$ & 1102 & 698 & 3,598495 & \\
\hline \multicolumn{3}{|c|}{ Total } & 17119 & 2278 & 11,74408 & \\
\hline
\end{tabular}




\section{Implementasi crew balance chart}

Dari hasil pengamatan dilapangan didapatkan data waktu dari setiap kegiatan yang dilakukan oleh pekerja, data tersebut merupakan data utama yang akan diolah dengan menggunakan metode crew balance chart. Dari hasil olahan tersebut akan dikaji waktu produktifitas pekerja dengan menggunakan crew balance chart. Pada tabel rekapitulasi waktu dapat diperoleh besaran persentase waktu produktif dan waktu tidak produktif pekerja. Dalam crew balance chart akan terlihat sub kegiatan dari masing - masing pekerja dalam mengerjakan pekerjaan plesteran dinding bata tersebut. Sehingga dapat dilihat keadaan kondisi pekerja dilapangan dalam menjalankan pekerjaannya. Dapat dilihat pada gambar 2 untuk digram crew balance chart.

Crew Balance Chart Plesteran Dinding Depan Hari ke-1
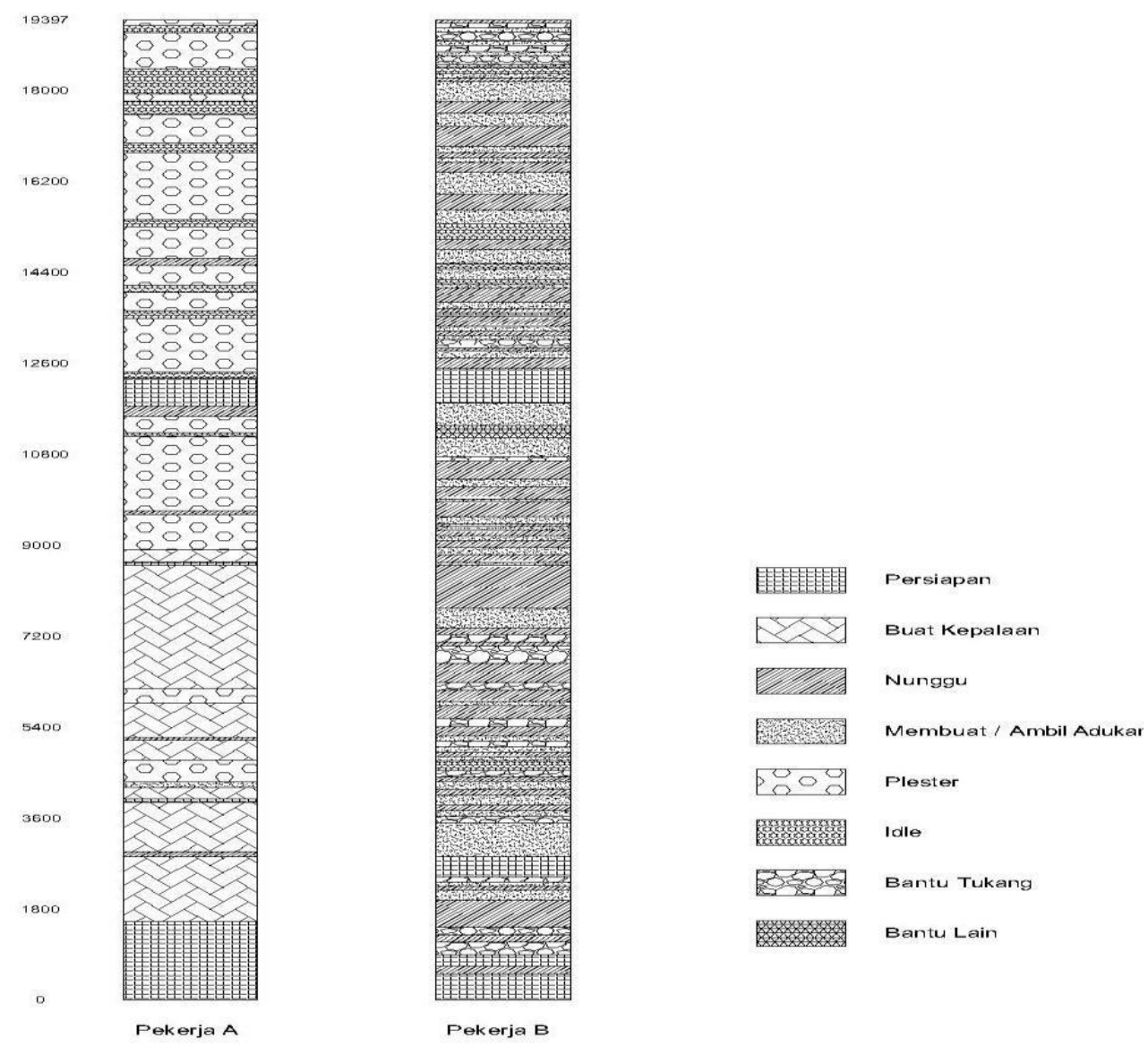

Gambar 2. Crew balance chart plesteran dinding

\section{Perhitungan produktivitas pekerja}

Perhitungan produktivitas pekerja dibagi menjadi 2 bagian, yaitu produktivitas keadaan kondisi lapangan, dan produktivitas tanpa idle, pada tabel 4 dapat dilihat perbandingan antara produktivitas kondisi lapangan dan produktivitas ideal.

\section{Perhitungan produktivitas hasil kerja pekerja di lapangan}

Plesteran Dinding Bagian Depan Hari ke-1

$$
\begin{aligned}
\text { Produktivitas } & =\frac{6,44 \mathrm{~m}^{2}}{19397 \text { detik }} \times 3600 \\
& =1,195 \mathrm{~m}^{2} / \mathrm{jam}
\end{aligned}
$$




\section{Perhitungan produktivitas pekerja tanpa idle}

Plesteran Dinding Bagian Depan Hari ke-1:

$$
\begin{aligned}
\text { produktivitas } & =\frac{100 \%}{(88,2559 \%+56,8181 \%) / 2} \times 1,195 \mathrm{~m}^{2} / \mathrm{jam} \\
& =1,6474 \mathrm{~m}^{2} / \mathrm{jam}
\end{aligned}
$$

Tabel 4. Perbandingan hasil perhitungan produktivitas lapangan dengan produktivitas ideal

\begin{tabular}{cccc} 
Area pengerjaan & Waktu pengerjaan & $\begin{array}{c}\text { Produktivitas lapangan } \\
\left(\mathbf{m}^{2} / \mathbf{j a m}\right)\end{array}$ & $\begin{array}{c}\text { Produktivitas ideal } \\
\left(\mathbf{m}^{2} / \mathbf{j a m}\right)\end{array}$ \\
\hline \multirow{2}{*}{ Depan } & Hari ke-1 & 1,1950 & 1,6474 \\
\cline { 2 - 4 } Belakang & Hari ke-2 & 3,9872 & 6,8694 \\
\cline { 2 - 4 } & Hari ke-1 & 0,4507 & 0,6426 \\
\hline \multirow{2}{*}{ Hari ke-2 } & 1,8123 & 2,4890 \\
\hline
\end{tabular}

\section{Analisis peningkatan produktivitas terhadap durasi kerja}

Dengan adanya peningkatan produktivitas kerja, maka waktu yang dibutuhkan untuk menyelesaikan suatu pekerjaan akan lebih singkat. Dari hasil olah data peningkatan produktivitas pekerja diatas, maka dapat kita perhitungkan waktu yang diperlukan untuk menyelesaikan pekerjaan plesteran dinding depan dan belakang tanpa adanya idle, dapat dilihat pada tabel 5.

Plesteran Dinding Bagian Depan Hari ke-1:

$$
\begin{aligned}
\text { Durasi kerja tanpa idle } & =\frac{1,195 \mathrm{~m}^{2} / \mathrm{jam}}{1,6474 \mathrm{~m}^{2} / \mathrm{jam}} \times 19397 \mathrm{detik} \\
& =14070,3017 \mathrm{detik}
\end{aligned}
$$

Tabel 5. Peningkatan produktivitas durasi pekerja

\begin{tabular}{cccc}
\hline \multirow{2}{*}{ Area pengerjaan } & Waktu pengerjaan & $\begin{array}{c}\text { Durasi kondisi lapangan } \\
\text { (detik) }\end{array}$ & $\begin{array}{c}\text { Durasi kondisi ideal } \\
\text { (detik) }\end{array}$ \\
\hline \multirow{2}{*}{ Depan } & Hari ke-1 & 19397 & 14070,3017 \\
\cline { 2 - 4 } & Hari ke-2 & 3245 & 1883,4926 \\
\hline \multirow{2}{*}{ Belakang } & Hari ke-1 & 10800 & 7574,7899 \\
\cline { 2 - 4 } & Hari ke-2 & 18572 & 13522,142 \\
\hline
\end{tabular}

Dari hasil perhitungan diatas penghematan waktu kerja masih bisa terjadi, bila pekerja dalam kondisi maksimal atau tanpa idle. Rentang waktu yang dapat dihemat cukup panjang bilamana pekerja dapat meningkatkan produktifitasnya, selisih waktu tersebut dapat digunakan sebagai persiapan untuk mengerjakan pekerjaan selanjutnya.

\section{Perhitungan analisis upah pekerja}

Perhitungan analisis pembayaran upah pekerja didapat dari koefisien pekerja, yang dimana koefisien tersebut didapat dari waktu produktif pekerja selama pengerjaan plesetran dinding bata berlangsung. Dengan adanya perhitungan analisis pembayaran upah pekerja ini, maka dapat kita hitung seberapa besar kerugian kontraktor akibat adanya waktu idle selama pekerjaan plesteran dinding berlangsung.

\section{Analisis perhitungan pembayaran upah pekerja}

Pada tabel 6 dan tabel 7 dapat dilihat besaran upah yang seharusnya dibayarkan oleh kontraktor kepada pekerja, dan berikut ini salah satu contoh perhitungan analisis pembayaran upah pekerja pada pekerjaan plesteran dinding bata, pada pekerja A (sebagai tukang) dihari pertama dengan waktu produktif sebesar 17119 detik dari total waktu pengerjaan selama 19397 detik. 


$$
\begin{array}{ll}
\text { Upah Harian } & =\text { Rp. } 150.000 \\
\text { Koefisien } & =\frac{\text { Total waktu produktif }}{\text { Total waktu kerja }} \times 100 \% \\
& =\frac{17119 \text { detik }}{19397 \text { detik }} \times 100 \% \\
& =88,2559 \% \\
\text { Upah pekerja } & =\text { koefisien } \times \text { harga upah harian pekerja } \\
& =88,2559 \% \times \text { Rp. } 150.000 \\
& =\text { Rp. } 132.384
\end{array}
$$

\begin{tabular}{|c|c|c|c|c|c|}
\hline Nama & Kegiatan & Waktu pengerjaan & $\begin{array}{c}\text { Koefisien } \\
(\%)\end{array}$ & Upah harian & $\begin{array}{c}\text { Jumlah } \\
\text { (Rp.) }\end{array}$ \\
\hline \multirow{2}{*}{ A } & \multirow{2}{*}{ I ukang } & Hari ke-1 & 88,2559 & \multirow{2}{*}{ IJU.UUU } & 132.384 \\
\hline & & Hari ke-2 & 88,1664 & & 132.250 \\
\hline \multirow{2}{*}{ b } & \multirow{2}{*}{ кепек } & Hari ke-1 & 56,8181 & \multirow{2}{*}{$1 \angle \mathrm{J} . \mathrm{UUU}$} & 71.023 \\
\hline & & Hari ke-2 & 27,9199 & & 34.900 \\
\hline \multicolumn{5}{|c|}{ Total } & 370.556 \\
\hline
\end{tabular}

\begin{tabular}{|c|c|c|c|c|c|}
\hline Nama & Kegiatan & $\begin{array}{c}\text { Waktu } \\
\text { pengerjaan }\end{array}$ & $\begin{array}{c}\text { Koefisien } \\
(\%)\end{array}$ & Upah harian & $\begin{array}{c}\text { Jumlah } \\
\text { (Rp.) }\end{array}$ \\
\hline \multirow{2}{*}{ C } & \multirow{2}{*}{ I ukang } & Hari ke-1 & 57,6389 & \multirow{2}{*}{ 1วU.vuv } & 86.458 \\
\hline & & Hari ke-2 & 71,5055 & & 107.258 \\
\hline \multirow{2}{*}{$\boldsymbol{\nu}$} & \multirow{2}{*}{ кепек } & Hari ke-1 & 82,6389 & \multirow{2}{*}{$1 \angle \supset . U U U$} & 103.299 \\
\hline & & Hari ke-2 & 74,1170 & & 92.646 \\
\hline \multicolumn{5}{|c|}{ Total } & 389.661 \\
\hline
\end{tabular}

Tabel 6. Upah pekerja plesteran dinding depan

Tabel 7. Upah pekerja plesteran dinding belakang

Analisis kerugian kontraktor

a) Pekerjaan Plesteran Dinding Bagian Depan

$$
\begin{aligned}
\text { Kerugian Total }= & \Sigma(\text { Harga satuan upah harian pekerja }- \text { Upah pekerja }) \\
= & (150.000-132.384)+(150.000-132.250)+(125.000-71.023)+(125.000- \\
& 34.900) \\
= & \text { Rp. } 179.444
\end{aligned}
$$

b) Pekerjaan Plesteran di Dinding Bagian Belakang

$$
\begin{aligned}
\text { Kerugian Total }= & \Sigma(\text { Harga satuan upah harian pekerja }- \text { Upah pekerja }) \\
= & (150.000-86.458)+(150.000-107.258)+(125.000-\text { aa103.299 })+(125.000- \\
& 92.646) \\
= & \text { Rp. } 160.339
\end{aligned}
$$




\section{KESIMPULAN DAN SARAN}

\section{Kesimpulan}

Berdasarkan hasil pengamatan dan pengolahan data pada penelitian ini, dapat disimpulkan sebagai berikut:

1. Pada pekerjaan plesteran dinding depan, waktu tidak produktif terbesar pada pekerja A sebesar $11,834 \%$ dengan nilai koefisien $88,166 \%$, dan pada pekerja B waktu tidak produktif terbesar mencapai $72,08 \%$ dengan nilai koefisien $27,919 \%$. Sedangkan pada pekerjaan plesteran dinding belakang waktu tidak produktif terbesar pada pekerja C mencapai sebesar 42,361\% dengan nilai koefisien 57,639, dan waktu tidak produktif terbesar pada pekerja D sebesar 25,883\% dengan nilai koefisien $74,117 \%$. Dari hasil perhitungan tersebut dapat disimpulkan pada group ke-1 dan group ke-2 memiliki perbedaan besaran nilai produktivitas, yang dimana pada pekerjaan plesteran dinding depan pembantu tukang (kenek) memiliki nilai persentase waktu tidak produktif lebih besar dari tukangnya. Sedangkan pada pekerjaan plesteran dinding belakang sebaliknya, nilai persentase waktu tidak produktif tukang lebih besar dari pembantu tukang (kenek).

2. Dari hasil pengamatan dilapangan total waktu yang dibutuhkan group kerja ke-1 untuk menyelesaikan pekerjaan plesteran dinding area depan selama 22.642 detik dengan total volume plesteran yang dihasilkan sebesar $10,034 \mathrm{~m}^{2}$ yang dimana bila pekerja dalam kondisi ideal pekerjaan plesteran tersebut dapat diselesaikan dalam waktu 15.953,79 detik. Sedangkan pada group kerja ke-2 total waktu yang dibutuhkan untuk menyelesaikan pekerjaan plesteran dinding area belakang selama 29.372 detik dengan total volume plesteran yang dihasilkan sebesar $10,702 \mathrm{~m}^{2}$ yang dimana bila pekerja dalam kondisi ideal pekerjaan plesteran tersebut dapat diselesaikan dalam waktu 21.096,93 detik. Bilamana peningkatan produktivitas dapat dilakukan, maka selisih waktu tersebut dapat digunakan untuk memulai persiapan pada pekerjaan selanjutnya.

3. Akibat rendahnya produktivitas pekerja pada group kerja ke-1 maupun group kerja ke-2, kontraktor mengalami kerugian pada pembayaran upah pekerja sebesar Rp. 179.443,00 pada pekerjaan plesteran dinding area depan. Sedangkan kerugian pada pekerjaan plesteran dinding area belakang sebesar Rp. 160.339,00. Sehingga seluruh total kerugian pada pekerjaan plesteran yang diamati sebesar Rp. 339.782,00 untuk total volume pekerjaan plesteran bagian depan maupun belakang sebesar $20,735 \mathrm{~m}^{2}$.

\section{Saran}

Berikut beberapa saran pada penelitian ini:

1. Dari hasil pengamatan didapatkan bahwa produktivitas pekerja dalam pekerjaan plesteran dinding bata memiliki persentase tidak produktif tertinggi sebesar $72 \%$, angka persentase tersebut menunjukkan bahwa peningkatan pengawasan secara berkala terhadap hasil kerja yang dilakukan pekerja sangatlah dibutuhkan, guna untuk menekan waktu tidak produktif pekerja dilapangan yang mengakibatkan kerugian biaya pada kontraktor.

2. Penelitian ini dapat dikembangkan dengan pengamatan yang berbeda, seperti penggabungan 2 group kerja dengan mengurangi salah satu pekerja pembantu tukang (kenek). Hasil dari penelitian tersebut kedepannya dapat dijadikan referensi perbandingan waktu produktif dan hasil volume yang dikerjakan dengan membandingkan antara pengerjaan plesteran dilakukan oleh 2 tukang dengan 2 kenek, dengan pengerjaan plesteran dilakukan oleh 2 tukang dengan 1 kenek.

\section{DAFTAR PUSTAKA}

Caroline, Denny. "Pengaruh Peningkatan Produktivitas Terhadap Durasi Pekerjaan Fabrikasi Besi pada Proyek Indonesia 1 dengan Metode Crew Balance Chart.” Jurnal Mitra Teknik Sipil (2018): 1-8.

Ervianto, Wulfram I. Manajemen Proyek Konstruksi, Edisi Revisi. Yogyakarta: Andi, 2005.

Muchdarsyah, Sinungan. Produktivitas Apa dan Bagaimana, Edisi Kedua. Jakarta: Bumi Aksara, 1992.

Purnomo, Soekirno. Metode Konstruksi I, Bangunan, Sistem Struktur, Teknologi dan Metode Konstruksi. Yogyakarta: Diktat Kuliah Magister Teknik Sipil UII, 2000. 
